Research, Society and Development, v. 9, n. 8, e918986569, 2020

(CC BY 4.0) | ISSN 2525-3409 | DOI: http://dx.doi.org/10.33448/rsd-v9i8.6569

Auditoria ambiental e sua importância como ferramenta de gestão ambiental Environmental audit and its importance as an environmental management tool Auditoría ambiental y su importancia como herramienta de gestión ambiental Recebido: 09/07/2020 | Revisado: 17/07/2020 |Aceito: 18/07/2020 | Publicado: 02/08/2020

\title{
Evandro Ferigato
}

ORCID: https://orcid.org/0000-0003-2044-1324

Centro Universitário Campo Limpo Paulista, Brasil

E-mail: evandroferigato@gmail.com

Márcio Magera Conceição

ORCID: https://orcid.org/0000-0001-6477-4580

Universidade Guarulhos, Brasil

E-mail: magera1963@gmail.com

\author{
Alessandro Marco Rosini \\ ORCID: https://orcid.org/0000-0002-5150-8483 \\ Universidade Anhanguera, Brasil \\ E-mail:alessandro.rossini@yahoo.com \\ Joelma Telesi Pacheco Conceição \\ ORCID: https://orcid.org/0000-0002-7045-6260 \\ Faculdade de Paulínia, Brasil \\ E-mail: Joelma.telesi@gmail.com
}

\begin{abstract}
Resumo
O propósito deste artigo é investigar as origens e o desenvolvimento da auditoria ambiental como uma técnica-chave de gerenciamento e como uma ferramenta de autorregulação que se acredita ter surgido em resposta à maior conscientização do público e das empresas sobre questões ambientais. Estudos voltados à caracterização da auditoria ambiental, à relação da auditoria ambiental com a contabilidade e a como fazer uma auditoria ambiental apontaram como resultado que uma das formas das empresas evidenciarem seu comprometimento com a questão ambiental é incluir, no gerenciamento do sistema ambiental, técnicas de auditoria ambiental que utilizem a contabilidade ambiental como ferramenta adequada à mensuração do desempenho ambiental das empresas, correção das distorções e aperfeiçoamento do controle na redução de impactos ambientais e patrimoniais nas organizações. Para embasamento do
\end{abstract}


referencial teórico, utilizaram-se de forma conceitual, os referenciais que nos é definido por estudiosos do ramo e com isso podemos demonstrar como a auditoria é de suma importância para a gestão ambiental de uma organização. Definimos a auditoria ambiental como uma ferramenta na qual auxilia a organização para que execute de forma eficiente e eficaz a qualificação e a licenciatura de qualificações técnicas. Foi possível constatar que o processo necessita de uma pessoa nomeada, o auditor líder e realizado pelos demais, visando sempre à busca pela avaliação do desempenho, concordância legal, comprometimento da organização das políticas ambientais de uma empresa. As obrigações empresariais com o meio ambiente são de suma importância para análise de funções, garantindo a conscientização do seu meio, funcionários, sociedade e afins, para que com isso tenhamos a prevenção e a preservação do meio ambiente e dos recursos naturais nele existente.

Palavras-Chave: Gestão ambiental; Auditoria ambiental; Políticas ambientais.

\section{Abstract}

The purpose of this article is to investigate the origins and development of environmental auditing as a key management technique and as a self-regulatory tool that is believed to have arisen in response to increased public and business awareness of environmental issues. Studies focused on the characterization of environmental auditing, the relationship between environmental auditing and accounting and how to do an environmental audit pointed out as a result that one of the ways in which companies demonstrate their commitment to the environmental issue is to include, in the system management environmental, environmental auditing techniques that use environmental accounting as an adequate tool for measuring the environmental performance of companies, correcting distortions and improving control in reducing environmental and patrimonial impacts on organizations. To support the theoretical framework, it was used in a conceptual way, the benchmarks defined by industry experts and with this we can demonstrate how the audit is of paramount importance for the environmental management of an organization. We define environmental auditing as a tool in which it helps the organization to carry out the qualification and licensure of technical qualifications efficiently and effectively. It was found that the process requires a nominated person, the lead auditor and carried out by the others, always seeking to assess performance, legal compliance, and commitment to the organization of a company's environmental policies. Business obligations to the environment are of paramount importance for analyzing functions, ensuring awareness of their environment, employees, society and the like, so that we have the prevention and preservation of the environment and the natural resources in it . 
Keywords: Environmental management; Environmental auditing; Environmental policies.

\section{Resumen}

El propósito de este artículo es investigar los orígenes y el desarrollo de la auditoría ambiental como una técnica de gestión clave y como una herramienta de autorregulación que se cree que surgió en respuesta a una mayor conciencia pública y empresarial sobre los problemas ambientales. Los estudios centrados en la caracterización de la auditoría ambiental, la relación entre la auditoría ambiental y la contabilidad y cómo realizar una auditoría ambiental señalaron como resultado que una de las formas en que las empresas demuestran su compromiso con el tema ambiental es incluir, en la gestión del sistema ambiental, Auditoría ambiental que utiliza la contabilidad ambiental como una herramienta adecuada para medir el desempeño ambiental de las empresas, corregir distorsiones y mejorar el control para reducir los impactos ambientales y patrimoniales en las organizaciones. Para respaldar el marco teórico, se utilizó de manera conceptual, los marcos definidos por expertos de la industria y con esto podemos demostrar cómo la auditoría es de suma importancia para la gestión ambiental de una organización. Definimos la auditoría ambiental como una herramienta en la que ayuda a la organización a llevar a cabo la calificación y licencia de calificaciones técnicas de manera eficiente y efectiva. Fue posible verificar que el proceso necesita una persona nominada, el auditor líder y llevado a cabo por los demás, siempre con el objetivo de buscar una evaluación del desempeño, un acuerdo legal y el compromiso de la organización de las políticas ambientales de una empresa. Las obligaciones corporativas con el medio ambiente son de suma importancia para el análisis de funciones, asegurando la conciencia de su entorno, empleados, sociedad y similares, de modo que con esto tengamos la prevención y preservación del medio ambiente y los recursos naturales que existen en él.

Palabras clave: Gestión ambiental; Auditoría ambiental; Políticas ambientales.

\section{Introdução}

Com o intuito de abordagem dos conceitos de auditoria ambiental o presente artigo visa em um todo na busca para compreendermos as metodologias utilizadas neste processo de auditoria. De acordo com o que está discriminada no anexo I da Resolução do Conselho Nacional do Meio Ambiente, a auditoria ambiental trata do processo metódico e documentado de verificar, executar e avaliar de uma forma concreta e especifica, com as analises feitas a partir de uma avaliação total dos processos acima, a organização com fins de auditoria tem 
como identificar se os eventos, atividades ou ate mesmo as informações da organização estão de acordo com o que este previsto dentro dos critérios de auditoria na resolução e com isso os mesmos podem informar sobre as decorrências deste procedimento.

Conforme o disposto no Anexo I, da Resolução do Conselho Nacional do Meio Ambiente (CONAMA) n.306 (2002), a Auditoria Ambiental trata-se de:

Processo sistemático e documentado de verificação, executado para obter e avaliar, de forma objetiva, evidências que determinem se as atividades, eventos, sistemas de gestão e condições ambientais especificados ou se as informações relacionadas a estes estão em conformidade com os critérios de auditoria estabelecidos nesta Resolução, e para comunicar os resultados desse processo.

\section{Referencial Teórico}

Neste capítulo iremos apresentar a fundamentação teórica, objetivando em alicerçar a pesquisa com os seguintes temas:

- Visão geral de uma auditoria ambiental

- Surgimento da Auditoria Ambiental

- Princípios Gerais de Auditoria Ambiental

- Como é feita a auditoria ambiental no gerenciamento de resíduos

- Conceitos e definições

- Por que a auditoria ambiental na gestão ambiental é importante

- Tipos de auditoria ambiental

- Auditoria Ambiental e Avaliação de Impacto Ambiental

- Qual importância da auditoria ambiental no gerenciamento de resíduos

- Auditoria ambiental no gerenciamento de resíduos

- Vantagens da auditoria ambiental no gerenciamento de resíduos

- Procedimentos de auditoria

- Frequência de auditoria 


\subsection{Visão geral de uma auditoria ambiental}

As formas tradicionais de lidar com questões ambientais são esperar até que se tornem problemas e depois reagir mas eles fornecem resultados inadequados e ineficientes. $\mathrm{O}$ ambiente tornou-se uma consideração importante para qualquer tomada de decisões para o desenvolvimento de quaisquer organizações. Há um reconhecimento crescente de que as questões ambientais sãoassociado a quase todas as atividades de uma organização.

Uma maneira eficaz de abordar questões ambientais na organização é através do gerenciamento ambiental sistemático. As oportunidades de negócios são criadas quando os Sistemas de Gerenciamento Ambiental (SGA) fazem parte da prática diária dos negócios. Foi demonstrado em todo o mundo, em grandes e pequenas e médias empresas, que melhorou a qualidade ambientaldesempenho e economizar dinheiro. As empresas estão descobrindo que agir antes que ocorram problemas ambientais melhoracompetitividade e reduz custos também.

Um sistema de gestão ambiental bem-sucedido deve ser prático e flexível, adaptandose à natureza e às atividades específicas da empresa que o adota. Ele deve procurar evitar impactos ambientais, em vez de apenas oferecer uma cura. É muito fácil para uma autoridade se declarar "verde" e assumir compromissos ousados com a redução da poluição, protegendoespaços e assim por diante. É mais difícil e mais caro cumprir esses compromissos. Isso não pode ser alcançado da noite para o dia, ou mesmo necessariamente.

Os líderes empresariais cuja resposta inicial foi defensiva, agora estão convencidos da necessidade de ações mais proativas nos problemas ambientais. Entretanto, para responder efetivamente às pressões públicas e às regulamentações governamentais, o setor enfrentam inúmeras dificuldades no entendimento de suas obrigações, responsabilidades e direitos ao estabelecer e operar uma Unidade Industrial.

Colocar os sistemas de gestão ambiental em prática levará tempo. No entanto, são essenciais para qualquer estratégia para alcançar mudanças na escala exigida para o desenvolvimento sustentável - que é o desenvolvimento econômico destruindo os recursos naturais necessários para a geração futura.

Uma auditoria é uma avaliação do desempenho e dos recursos de uma organização em um campo específico. Não precisa haver nada misterioso de especial sobre isso. Qualquer tentativa de avaliar as atividades de uma organização, que olhe honestamente para ambos e características negativas, podem ser descritas como uma auditoria (Jacobs, 1991). A forma da auditoria deve ser determinada pelos objetivos da organização que a realiza. 
A auditoria ambiental é principalmente uma questão técnica de coleta de dados ambientais. Este pode ser um aspecto importante, particularmente na análise do estado do ambiente real. Mas, finalmente, a auditoria é uma questão de gerenciamento. Seus resultados devem ser a melhor coordenação dos objetivos corporativos, objetivos políticos individuais, sistemas de informação, tomada de decisão, procedimentos, orçamento, recursos humanos, estrutura organizacional e métodos de comunicação, para alcançar maior Qualidade

Ambiental. É por isso que uma auditoria eficaz deve fazer parte e contribuir para uma estratégia para a autoridade. A auditoria ambiental deve identificar claramente as áreas sobre as quais as prioridades e escolhas precisam ser, deve ser decidido e deve impedir as informações ambientais de maneira a facilitar a tomada de decisões. Ao conduzir a auditoria ambiental, a equipe da autoridade é o principal recurso. A auditoria deve, portanto, ser realizada em plena consulta e colaboração com a equipe. Eles devem ser conscientizados sobre o que é auditoria e o que não é, ou seja, não é um exercício de policiamento e por que está sendo realizado. Eles devem ser encorajados a se envolver, e sua confiança precisa ser vencido. Seminários de conscientização e treinamento são, portanto, uma parte importante da auditoria ambiental.

\subsection{Surgimento da auditoria ambiental}

A auditoria ambiental é mais frequentemente vista como uma ferramenta de gerenciamento ambiental empregada pelas empresas para facilitar um melhor gerenciamento de seu desempenho ambiental. Embora a auditoria ambiental não seja definida com precisão, um consenso crescente em torno de um amplo grupo de critérios sugere que vários tipos de auditoria se enquadram no termo geral. Por outro lado, existem algumas atividades que são inadequadamente referidas como auditorias ambientais. Alguns códigos ambientais voluntários mencionam especificamente a auditoria ambiental, mas esses códigos parecem não ter suporte nas empresas e parece não ter credibilidade. Garantir a credibilidade das auditorias ambientais junto às partes interessadas pode ser auxiliado por uma avaliação externa independente do processo. A singularidade da auditoria ambiental parece surgir da amplitude dos assuntos abordados no processo, da variedade de medidas e dos diferentes tipos de dados coletados e das habilidades necessárias para realizar uma auditoria ambiental, e não das técnicas empregadas.

De acordo com todas as situações ambientais vistas ao decorrer dos anos, quando uma empresa não possui uma responsabilidade ambiental e automaticamente a responsabilidade 
socioambiental, pode-se definir como as catástrofes que ocorrem ao decorrer do tempo, desta forma, todos os tipos de acontecimentos naturais que ocorrem ao decorrer do tempo, não necessariamente faz jus ao nome 'desastre natural' por ter uma grande influencia do ser humano nos acontecimentos ambientais. Com isso, as empresas por terem uma parcela grande de geradora de recursos nos quais prejudicam o meio ambiente se foram necessárias normas e legislações nas quais as empresas teriam de atender para continuar seu funcionamento sem uma devastação maior do meio.

A auditoria em si, tinha como foco principal apenas a saúde e o bem estar dos trabalhadores, porém quando se verificou a necessidade de restrições das empresas para com o meio ambiente, foi visto como algo a ser considerado plausível, uma vez que a organização esta ligada ao meio e ao bem estar das pessoas. Com isso em 1968 foi realizado a fundação do Clube de Roma, e com isso os temas que são ligados ao desenvolvimento sustentável e também ao meio ambiente se tornaram pautas a ser tratadas com mais seriedade.

Barbieri (2007) identifica as influências exercidas pela sociedade, pelo governo e o mercado sobre as empresas, com relação à questão ambiental, mostrando que essas influências interagem e impulsionam avanços, conforme mostrado na Figura 1:

Figura 1 - Gestão ambiental empresarial.

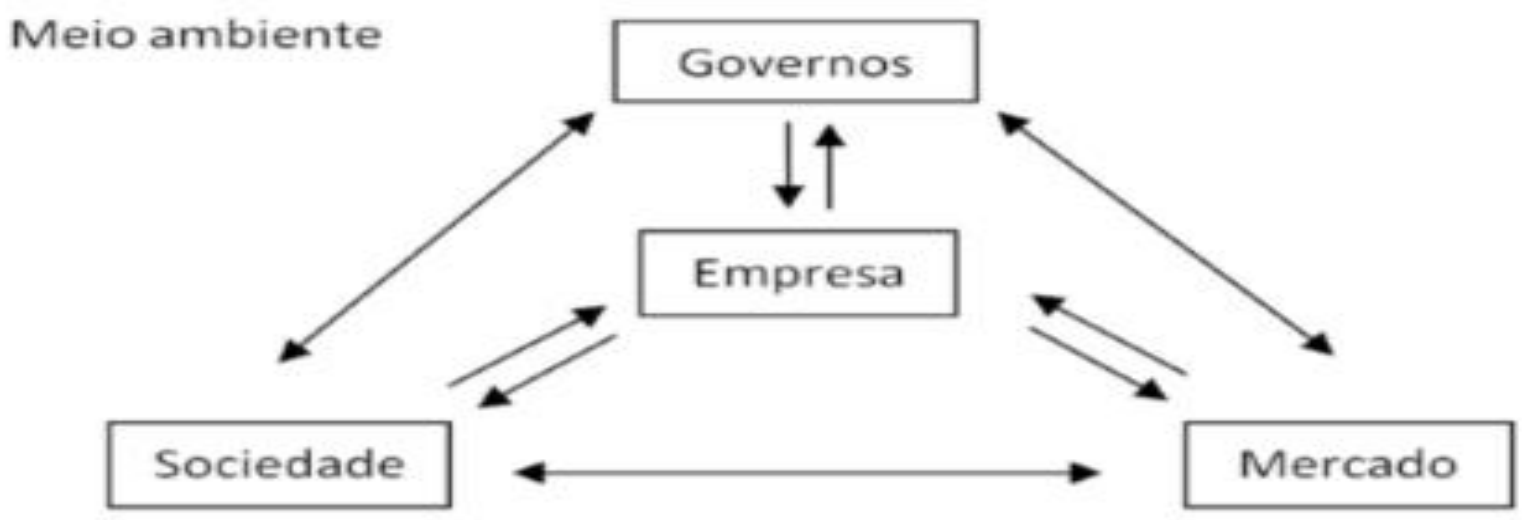

Fonte: Barbieri (2007).

Segundo Seiffert (2010), se torna um padrão para adotarmos novos métodos que preservassem os recursos e busquem um maior desenvolvimento e desempenho sustentável, para então ser durável para as necessidades da sociedade para que tenha uma melhor qualidade de vida. 
Research, Society and Development, v. 9, n. 8, e918986569, 2020

(CC BY 4.0) | ISSN 2525-3409 | DOI: http://dx.doi.org/10.33448/rsd-v9i8.6569

É de extrema importância evidenciar a definição de sustentabilidade, quando exposto como um modelo para que tenhamos um desenvolvimento que tenha pontos de vista tecnológicos.

[...] a) não utilizar recursos renováveis (florestas, solos, água, animais) em uma velocidade superior à requerida para sua renovação; b) não consumir os recursos não renováveis (combustíveis fosseis, minerais) a uma velocidade superior à que se necessita para encontrar substituto para eles; c) não produzir elementos contaminantes a uma velocidade superior à que a Terra exige para assimilá-los e absorvê-los. (Daly (1996 apud Martins; Soler; Soares 2001:163)

Conforme citado, o ponto de vista do autor menciona apenas recursos tecnológicos e ecológicos, não identificando os pontos de vista da sociedade, cultura e politicas em um todo. Desta forma, a politica de realizar uma auditoria ambiental se faz necessária para fins de um instrumento que a empresa dispõe para que seus processos sejam verificados e efetivados de formas ecológicas, para mencionar se os seus processos produtivos, seus equipamentos possuem a capacidade de utilizar de forma correta de nossos recursos naturais. Os aspectos que definem a verificação são:

- $\quad$ Normas técnicas

- $\quad$ Indicadores ambientais e;

- Os marcos legais.

Todos esses indicadores para a veracidade são relacionados a processos estadistas, sendo primeiramente a predominação dos processos ambientais definidos pela politica estatal, em segundo lugar esta em predominação as politicas adotadas pela própria organização quando realizado os processos institucionais e por fim, mas não menos importante, as politicas cientificas abordadas durante os processos da empresa principalmente no ramo químico.

Sendo assim, os indicadores predefinidos desta metodologia o auditor ou a equipe de auditoria pode condicionar as metas necessárias para se alcançar o objetivo final e com isso sejam aceitos para a avaliação geral do desempenho da organização com a gestão do meio ambiente. Com isto, a implementação de sistemas que fazem o gerenciamento ambiental e as cerificações da área, são definidos por empenhos dos setores produtivos da empresa e ter a 
responsabilidade de responder com veracidade a todos os questionários realizados pelos auditores, pois de nada adianta a implementação de uma forma na qual gerencie um sistema se o mesmo não puder ser alimentado com fontes nas quais tornam o processo real e de acordo com os discernimentos definidos, a função de avaliar os instrumentos de veracidade é realizada exclusivamente pelo auditor.

Para uma auditoria eficaz, podemos definir que os conceitos realizados pela auditoria ambiental são semelhantes aos conceitos de auditoria na contabilidade, onde o mesmo vai definir de forma balanceada as formas se é feito o uso dos recursos naturais, as definições passivas ambientais que são determinadas pelos problemas que as empresas enfrentam devido à responsabilidade com o meio ambiente, como quando a empresa faz o descarte de produtos químicos nos rios, quando utilizam a contaminação e de solo e afins.

Destacando também que a meta principal da criação da auditoria se dá a verificação do cumprimento da lei das organizações com o meio ambiente. Nas empresas norte-americanas a auditoria era vista como uma forma de prevenir qualquer custo a mais com a legislação que a empresa viesse a ter, pois a mesma é uma ferramenta eficaz para a antecipação de reparos, saúde, reorganização do meio e também para que as empresas pudessem utilizar as mesmas para reivindicar quando algo não ocorresse conforme o previsto.

Porém, no Brasil o termo auditoria ambiental é considerado como novo, por ter se fundado após o século XX e as auditorias são mais comuns em países mais desenvolvidos e logo após este período vem sendo cada vez mais aplicável em países que ainda se encontram em fase de desenvolvimento. Atualmente para a cerificação da norma ISSO 14001 (2004), as empresas veem buscando um desempenho maior para que assim seja verificada e possam ter um incremento e rigor para a legislação ambiental.

No ano de 1996 as normas ISO foram modificadas pela Associação Brasileira de Normas Técnicas (ABNT) e substituída pena NBR IS0 14010 (1996), 14011 (1996) e 14012 (1996) que são relacionadas a auditorias ambientais, mas logo após foi também substituída pela ABNT NBR ISO19011 (2002), que foi definida como a ISO 19011(2012). Com esta definição foi estabelecida e constatada as alterações da ampliação do escopo de auditoria e sistema de gerenciamento da gestão de qualidade e o meio para auditorias de sistemas de gestão de qualquer natureza ambiental. Ainda de acordo com a ISO 19011 foi introduzido métodos nos quais a auditoria remota e os conceitos de riscos adotassem uma nova forma, fornecer orientações nas quais gerencie programas de auditoria e estabeleça metas nas quais levam a objetivos reais para a coordenação de atividades. 
Research, Society and Development, v. 9, n. 8, e918986569, 2020

(CC BY 4.0) | ISSN 2525-3409 | DOI: http://dx.doi.org/10.33448/rsd-v9i8.6569

O principal objetivo da ISO 14000 e de suas normas é garantir o equilíbrio e proteção ambiental, prevenindo a poluição e os potenciais problemas que esta poderia trazer para a sociedade e economia, conforme a Tabela 1 abaixo:

Tabela 1 - Normas da série ISO 14000 dedicadas ao SGA e norma ISO 19011 destinada à auditoria de sistemas de gestão.

\begin{tabular}{|c|c|c|c|c|c|c|}
\hline \multicolumn{3}{|c|}{ INTERNACIONAL } & \multicolumn{3}{|c|}{ BRASIL } & \multirow{3}{*}{ Descrição } \\
\hline \multicolumn{3}{|c|}{ Comitê ISO/TC 207} & \multicolumn{3}{|c|}{ Comite ABNT/CB 38} & \\
\hline Norma & Publicação & Revisão & Norma & Publicação & Revisão & \\
\hline $\begin{array}{l}150 \\
14001\end{array}$ & 1996 & 2004 & $\begin{array}{l}\text { NBR } \\
\text { ISO } \\
14001 \\
\end{array}$ & 1996 & 2004 & $\begin{array}{l}\text { Sistemas de Gestão Ambiental } \\
\text { - Requisitos com Orientações } \\
\text { para Uso }\end{array}$ \\
\hline $\begin{array}{l}150 \\
14004\end{array}$ & 1996 & 2004 & $\begin{array}{l}\text { NBR } \\
\text { ISO } \\
14004\end{array}$ & 1998 & $\begin{array}{l}1998,2004 \\
\text { e } 2005\end{array}$ & $\begin{array}{l}\text { Sistemas de Gestão Ambiental } \\
\text { - Diretrizes Gerais sobre } \\
\text { Princípios, Sistemas e Técnicas } \\
\text { de Apoio }\end{array}$ \\
\hline $\begin{array}{l}\text { ISO } \\
14010\end{array}$ & 1996 & \multirow{3}{*}{$\begin{array}{l}\text { Canceladas } \\
\text { e substi- } \\
\text { tuídas pela } \\
\text { norma ISO } \\
19011 \text { em } \\
2002\end{array}$} & $\begin{array}{l}\text { NBR ISO } \\
14010\end{array}$ & 1996 & \multirow{3}{*}{$\begin{array}{l}\text { Canceladas } \\
\text { e substi- } \\
\text { tuídas pela } \\
\text { norma NBR } \\
\text { ISO } 19011 \\
\text { em } 2002\end{array}$} & $\begin{array}{l}\text { Diretrizes para Auditoria } \\
\text { Ambiental - Princípios Gerais }\end{array}$ \\
\hline $\begin{array}{l}\text { ISO } \\
14011\end{array}$ & 1996 & & $\begin{array}{l}\text { NBR ISO } \\
14011\end{array}$ & 1996 & & $\begin{array}{l}\text { Diretrizes para Auditoria } \\
\text { Ambiental - Procedimentos de } \\
\text { Auditoria }\end{array}$ \\
\hline $\begin{array}{l}\text { ISO } \\
14012\end{array}$ & 1996 & & $\begin{array}{l}\text { NBR ISO } \\
14012\end{array}$ & 1996 & & $\begin{array}{l}\text { Diretrizes para Auditoria } \\
\text { Ambiental - Critérios de } \\
\text { Qualificação para Auditores } \\
\text { Ambientaîs } \\
\end{array}$ \\
\hline $\begin{array}{l}\text { ISO } \\
19011\end{array}$ & 2002 & 2011 & $\begin{array}{l}\text { NBR ISO } \\
19011\end{array}$ & 2002 & 2012 & $\begin{array}{l}\text { Diretrizes para auditoria de } \\
\text { sistemas de gestão }\end{array}$ \\
\hline
\end{tabular}

Fonte: Martins (2015).

\subsection{Princípios gerais de auditoria ambiental}

A ISO 14010 descreve os princípios gerais da auditoria ambiental, que também se aplicam a uma auditoria. O documento foi escrito com todos os casos possíveis em mente, portanto, não apenas para pessoas de dentro da organização que realizam auditorias de sua própria organização, mas também para auditorias externas. Portanto, foi feita uma distinção entre um cliente (a organização comissionamento da auditoria) e o auditado (a organização a ser auditada). Nas grandes organizações, essa distinção também é valiosa: a parte da organização a ser auditada pode ser diferente da parte da organização que deseja ter a auditoria a ser realizada. Estes princípios gerais são:

- Deveria ficar claro que haveria informações suficientes disponíveis sobre o assunto da auditoria. Deve também 
Research, Society and Development, v. 9, n. 8, e918986569, 2020

(CC BY 4.0) | ISSN 2525-3409 | DOI: http://dx.doi.org/10.33448/rsd-v9i8.6569

- Deveria ficar claro que haveria informações suficientes disponíveis sobre o assunto da auditoria. Deve também fique claro que existem recursos adequados disponíveis (tempo, assistência) e que existe cooperação suficiente de o auditado.

- Antes de uma auditoria iniciar, os objetivos e o escopo devem ser claros. Este é um trabalho para o auditor juntamente com o cliente. Uma vez estabelecidos, o auditado também deve ser informado.

- Um ponto delicado é garantir a objetividade e a independência do(s) auditor(es). Eles devem ser independentes de as atividades que auditam. Isso significa que não se devem auditar as atividades dos próprios departamentos. Em organizações maiores essa independência é mais fácil do que nas menores. É mais fácil usar auditores de outros locais ou outros departamentos. A competência é outro princípio relacionado aos auditores: eles devem possuir uma combinação de conhecimento, habilidade e experiência para a auditoria específica.

- Um auditor deve sempre trabalhar de acordo com as expectativas gerais sobre como os auditores devem agir, descrito no documento como o devido cuidado profissional. Parte disso é estar ciente e levar em consideração os requisitos sobre confidencialidade e discrição, bem como usando procedimentos de garantia de qualidade.

- Um auditor deve seguir procedimentos bem definidos. ISO 14011 é recomendado para a realização de uma auditoria.

- Outro princípio é que, em uma auditoria, é necessário um critério, que esteja vinculado aos objetivos da auditoria. $\mathrm{O}$ auditor coleta evidências que podem ser comparadas com os critérios e isso lhes dará conclusões: está de acordo com os critérios ou não (o último é então uma constatação de não conformidade de não conformidade).

- Como em toda auditoria apenas uma amostra das informações disponíveis será usada, os resultados da auditoria devem sempre ser usado levando em consideração esse fator de incerteza. Mas o mais importante é saber que sempre usaremos uma amostra, deve-se levar em consideração no planejamento e execução da auditoria: se 
Research, Society and Development, v. 9, n. 8, e918986569, 2020

(CC BY 4.0) | ISSN 2525-3409 | DOI: http://dx.doi.org/10.33448/rsd-v9i8.6569

houver várias áreas de risco, a auditoria das atividades deve ser planejada de modo que pelo menos essas áreas de risco sejam adequadamente levadas em consideração. Confiabilidade da auditoria. A descoberta também desempenha um papel se alguém quiser apresentar conclusões gerais de auditoria com base nas descobertas: então é importante que a chance de perder resultados significativos seja mínima.

- Relatar os resultados da auditoria é outro princípio.

Na Figura 2, é possivel visualizar que a auditoria é um recurso que deve estar presente na realidade de qualquer empresa, pois é ela que oferece aos gestores a garantia de que os processos estão sendo corretamente realizados, ou seja, feitos de maneira otimizada e em conformidade com a legislação.

Figura 2 - Elementos essenciais para o sucesso das auditorias.

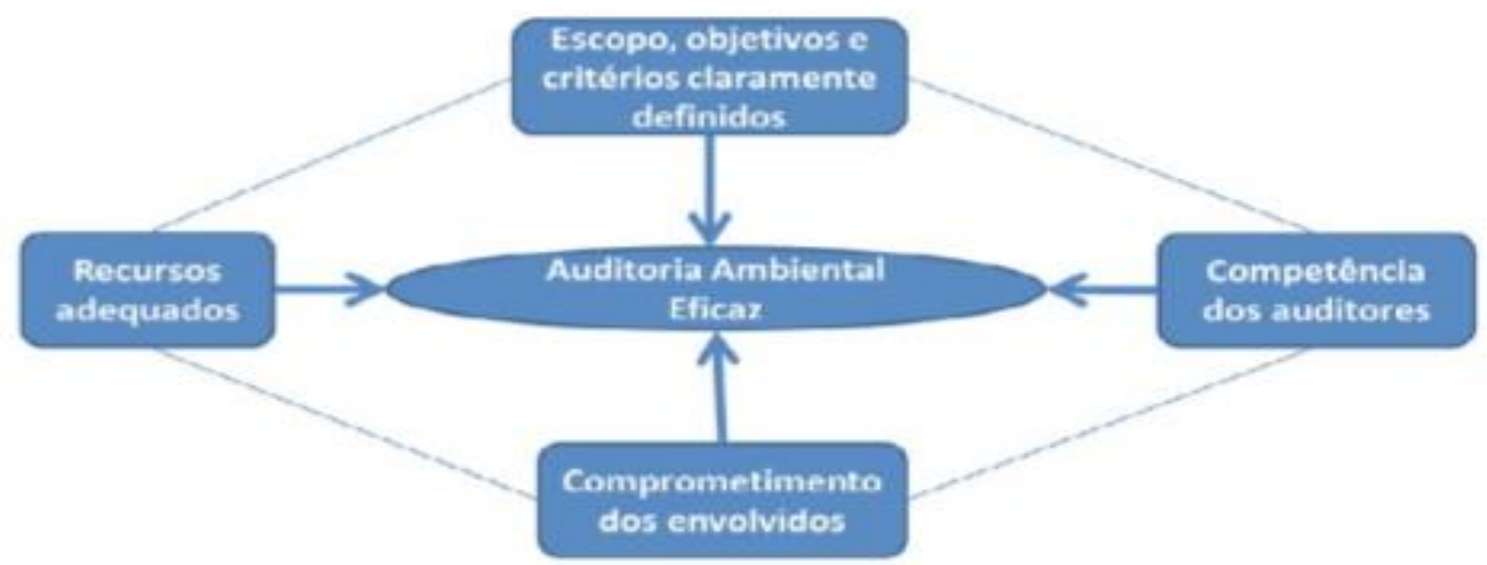

Fonte: Villela, (2006/2013).

\subsection{Como é feita a auditoria ambiental no gerenciamento de resíduos}

A auditoria ambiental no gerenciamento de resíduos pode ser realizada em três fases. São elas:

\section{- Auditoria ambiental de pré-avaliação:}

Nesta fase engloba-se a preparação da auditoria. São obtidas informações sobre o processo. Essas informações são importantes para identificar cada etapa do processo e quais os resíduos gerados. Após isso, é elaborado o fluxograma das áreas que serão auditadas. 


\section{- Auditoria ambiental de inspeção:}

Depois de identificado cada etapa dos processos da empresa e com o fluxograma em mãos é realizado uma verificação visual, de amostragem e classificação dos resíduos. Além disso, é avaliado o balanço de massa (ou seja, as verificações de entradas e saídas).

Durante a auditoria ambiental de inspeção é verificado se a empresa cumpre os requisitos exigidos pelas leis de gestão de resíduos, tais como: possibilidade de não geração, redução, reciclagem, tratamento e disposição final.

Também, são avaliadas forma de acondicionamento, armazenamento, tratamento e transporte dos resíduos. Se forem cumpridos as normas pertinentes a cada uma delas de acordo com o tipo de resíduo gerado. Bem com se os fornecedores contratados cumprem com a legislação e possuem licenças.

A organização deve comprovar se possuem um sistema de logística reversa bem implementado, caso a lei exija dela o sistema.

\section{- Síntese:}

$\mathrm{Na}$ terceira fase do processo de auditoria ambiental é realizado o relatório final com as informações obtidas.

Todos os processos de Auditoria Interna Ambiental devem ser realizados cerca de um mês antes da Auditoria Externa. Essa auditoria interna deve ser feita por um órgão regulador. Em conformidade, a organização recebe o certificado de conformidade legal.

Todos os auditores são capacitados para tal, pois passa por vários tipos de treinamentos e cursos de capacitação, como Curso de Auditoria Interno e Curso de Auditor Líder.

Os auditores conferem as documentações referentes ao gerenciamento de resíduo. Após a auditoria, os auditores geram um relatório informando à empresa como está sua conformidade em relação à gestão de resíduos. Em caso de necessidade apontam observações de melhorias e não conformidades que precisam ser tratadas.

A partir de um gerenciamento de resíduos efetivo, ou seja, se cada etapa do gerenciamento estiver em conformidade com as normas e legislações pertinentes são possíveis alcançar a prevenção e minimização dos resíduos.

A utilização de um software de gestão de resíduos que monitora, diagnostica e controla as licenças é a melhor estratégia para a organização se manter em conformidade. 
Research, Society and Development, v. 9, n. 8, e918986569, 2020

(CC BY 4.0) | ISSN 2525-3409 | DOI: http://dx.doi.org/10.33448/rsd-v9i8.6569

O software auxilia a monitorar o volume de geração e qual a destinação dada a cada tipo de resíduo. Além disso, a plataforma possui diversas funcionalidades inteligentes para empresa, como:

- auxilio através de big data e inteligência artificial que ajuda a otimizar processos e reduzir custos;

- controle de prestadores de serviços, documentos e licenças ambientais exigidas. Afastando assim, os impactos ambientais e preservando a imagem da empresa;

- geração de relatórios anuais automaticamente.

Sendo assim, a auditoria ambiental no gerenciamento de resíduos busca verificar e avaliar a situação do gerenciamento dos resíduos gerados na empresa. Confrontando se a organização segue as normas e legislações pertinentes à gestão de resíduos

Contratar uma empresa especializada em gestão ambiental para ficar em dia com todas as licenças e certificados ambientais obrigatórios, demonstra comprometimento com a sustentabilidade, com as leis em vigor e é também um diferencial competitivo no mercado.

Afinal, por meio dela é possível prevenir riscos ambientais, melhorar a imagem do empreendimento, otimizar a elaboração de relatórios e inventários e auxiliar no cumprimento de prazos.

Muitas atividades realizadas em empresas de diferentes segmentos e portes são consideradas potencialmente poluidoras, principalmente o descarte dos resíduos produzidos por elas. Sendo assim, diversos aspectos são considerados para fazer uma identificação de riscos, analisar as atividades e enfim elaborar um plano de ação, que comporta as respostas para cada risco encontrado conforme a Tabela 2: 
Tabela 2 - Fases e ciclos da Auditoria e seus respectivos Responsáveis.

\begin{tabular}{|c|c|}
\hline Fase do Ciclo da Auditoria & Responsáveis \\
\hline Programar a auditoria & Cliente interessado na auditoria \\
\hline Preparar a auditoria & \multirow{3}{*}{ Auditor ou equipe auditoria autorizada } \\
\hline Conduzir e avaliaar a auditoria & \\
\hline Preparar o relatório para o cliente & \\
\hline Analisar criticamente os resultados & Clientes interessado na auditoria \\
\hline $\begin{array}{l}\text { Concluir a auditoria empreendendo as } \\
\text { açôes corretivas }\end{array}$ & Auditado \\
\hline $\begin{array}{l}\text { Acompanhar as açôes corretivas } \\
\text { empreendidas }\end{array}$ & Auditor ou equipe auditora autorizada \\
\hline
\end{tabular}

Fonte: Cerqueira (2005).

\subsection{Conceitos e definições}

Há pouco consenso sobre a definição de auditorias ambientais na literatura acadêmica, provavelmente porque essas auditorias podem estar associadas a uma ampla gama de atividades (Hillary, 1998; De Moor e De Beelde, 2005).

A auditoria ambiental vem se destacando por ser uma ferramenta essencial da gestão ambiental, ela se define em um processo metódico e formal de verificação, pela parte de auditoria. Atua-se de forma objetiva em condutas e desempenhos ambientais de organizações, averiguando se as mesmas atendem ao conjunto de critérios que são especificados pela legislação ambiental vigente assegurando que as empresas estão adequadas as leis ambientais com uma postura mais defensiva.

Segundo La rovere (2011) A auditoria ambiental é como um instrumento que ajuda as organizações a controlar o atendimento as políticas praticas e procedimentos, para assim, obter um controle e uma segurança maior referente ao desempenho ambiental, também principalmente para evitar possíveis acidentes.

No Brasil existem vários tribunais municipais e estaduais que fazem as auditorias ambientais, onde o governo cada vez mais tem adotado leis que ajudam na fiscalização ambiental, utilizando da política publica e programas de apoio que são focados para diversas questões da biodiversidade do país.

Segundo Barbieri (2007, p. 190) a expressão Auditoria Ambiental: 
Tornou-se bastante elástica, podendo significar uma diversidade de atividades de caráter analítico voltadas para identificar, averiguar e apurar fatose problemas ambientais de qualquer magnitude e com diferentes objetivos.

Em sua forma mais comum, a auditoria ambiental é uma série de atividades realizadas por iniciativa de uma organização em gestão para avaliar o desempenho ambiental. Além dessa base comum, o termo "auditoria ambiental" tem associar-se a uma ampla variedade de esforços, atividades e programas (Anon, 1991). Enquanto algumas empresas a usam para descrever os esforços baseados principalmente no julgamento profissional, os programas mais sofisticados são distinguidos por uma abordagem sistemática e objetiva para verificar a conformidade ambiental e o sistema em vigor para gerenciar responsabilidades ambientais. Em outras palavras, a auditoria é um exame metodológico, análises de faturas, testes e confirmações das instalações de uma instalação, procedimentos e práticas com o objetivo de verificar se cumprem os requisitos legais e políticas internas eavaliar se estão em conformidade com as boas práticas ambientais. Nesse contexto, os auditores baseiam seus julgamentos sobre conformidade com as evidências reunidas durante a auditoria e documentadas nos documentos de trabalho do auditor. De Meio Ambiente portanto, a auditoria difere das avaliações ou inspeções, que oferecem uma opinião baseada principalmente no julgamento profissional. O termo "auditoria" tornou-se associado a uma ampla variedade de esforços, atividades e programas destinados aexaminar o desempenho de uma determinada instalação ou operação e determinar em que medida essas atividades eos programas cumprem os requisitos externos e os padrões internos. A Posição da Câmara Internacional de Comércio (1989), sobre Auditoria Ambiental, define as normas ambientaisauditoria da seguinte forma: "Uma ferramenta de gerenciamento que compreende uma avaliação sistemática, documentada, periódica e objetiva de quão bem a organização, o gerenciamento e o equipamento estão funcionando com o objetivo de ajudar a proteger o meio ambiente através de: (i) facilitar o controle gerencial das práticas ambientais; e (ii) avaliar o cumprimento das políticas da empresa, queincluiria o cumprimento de requisitos regulatórios". A Organização Internacional de Padronização (ISO) incluiu auditoria ambiental em sua missão e desenvolveu três padrões de auditoria ambiental, abordando princípios gerais, conduzindo auditorias de sistemas de gestão e qualificações do auditor. A ISO 14010 fornece princípios gerais que podem ser usados em todos os tipos deauditorias ambientais. Isso inclui: (1) escopo e objetivo claramente definidos; (2) objetividade, independência ecompetência dos auditores; (3) uso do devido cuidado profissional pelos auditores; (4) 
procedimentos sistemáticos para conduzir a auditoria; (5) uso de critérios de auditoria, coleta de evidências de auditoria e descobertas documentadas; (6) resultados confiáveis de auditoria e conclusõessiões; e (7) relatório escrito das constatações da auditoria. Da mesma forma, a ISO 14011/1 fornece procedimentos para a realização de auditorias de Sistemas de Gestão. Elementos específicos incluem a definição dos objetivos da auditoria; determinar papéis, responsabilidades e atividades de auditores, clientes e auditado; realizar a auditoria; e relatórios de resultados. Da mesma forma, os endereços ISO 14012, as qualificações dos auditores, como educação e experiência no trabalho, treinamento, atributos e habilidades pessoais, competênciana prática de auditoria, devido atendimento profissional e habilidades de linguagem e comunicação. (Ross, 1996). A ISO 14010 apresenta uma definição geral de auditoria ambiental; A ISO 14011 adiciona uma grande mais específica definição de uma auditoria. Essas definições são lidas da seguinte forma:

Auditoria ambiental: um processo sistemático de verificação documentada para obter e avaliar objetivamente as evidências de auditoria e determinar se atividades, eventos, condições, sistema de gerenciamento ou informações ambientais, esses assuntos, estão de acordo com os critérios de auditoria e comunicam os resultados desse processo ao cliente (ISO 14010).

Os trabalhos de auditoria ambiental devem ser desenvolvidos à maneira da auditoria interna operacional, em função de semelhança de seus propósitos enquanto instrumentos de apoio ao processo decisório, demosntrados na Figura 3:

Figura 3 - Modelos dos estágios de auditoria ambiental.

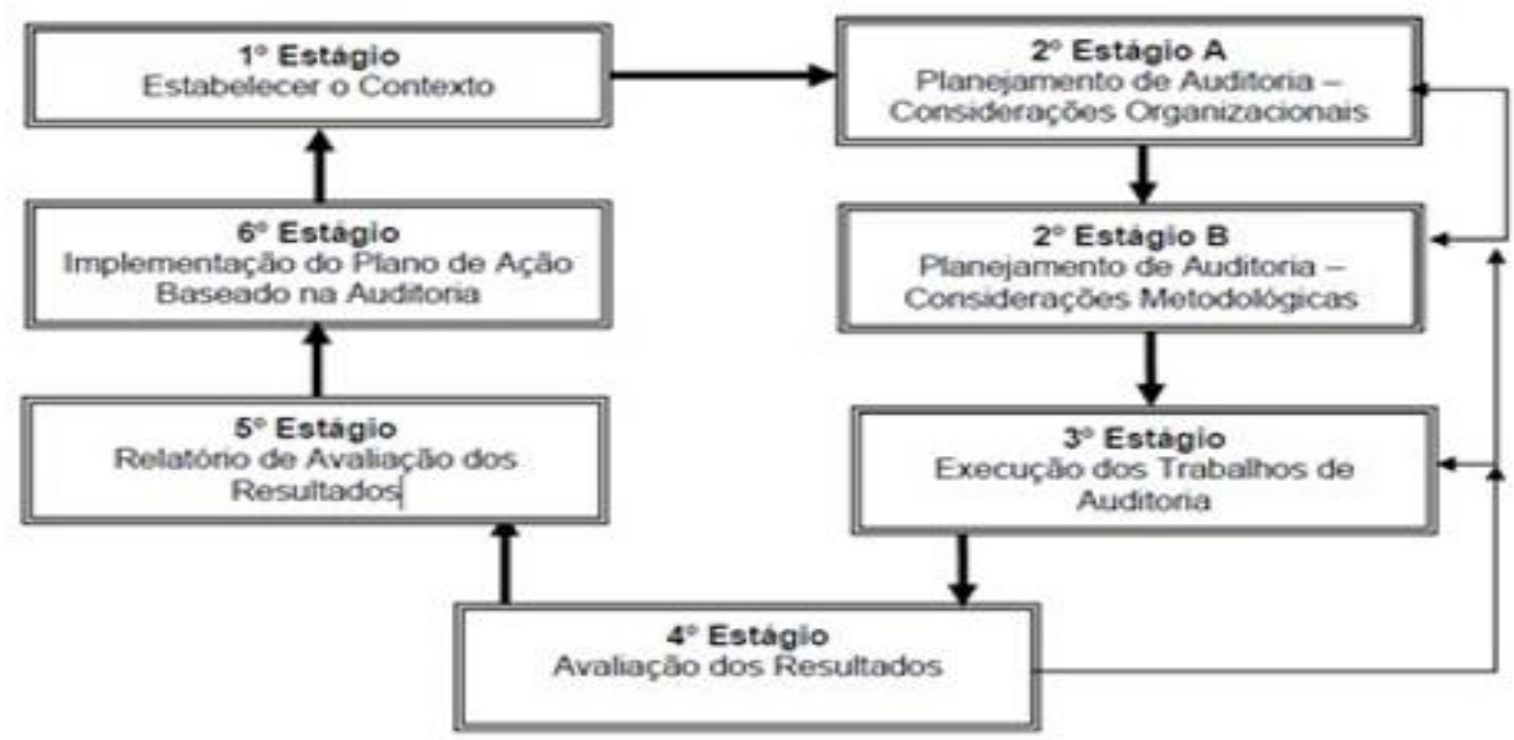

Fonte: Ledgerwooxd; Street and Therivel (1992) adaptado por Oliveira Filho (2002). 


\subsection{Por que a auditoria ambiental na gestão ambiental é importante}

Existem razões pelas quais a auditoria ambiental ainda é cercada por alguma confusão. A primeira é que as pessoas assumem deve haver algum paralelo entre auditoria financeira e ambiental. Este não é o caso. Uma auditoria financeira é uma verificação externa das contas preparadas internamente de uma organização. Uma auditoria ambiental não é verificação nem precisa ser conduzido externamente. Além disso, uma auditoria financeira é simplesmente um processo de 'verificação'. Por outro lado, uma auditoria ambiental é um processo substantivo. Deveria ter pelo menos três elementos diferentes (Jacobs, 1991):

1. Uma descrição e avaliação da situação atual no campo sob auditoria;

2. Recomendações de objetivos para a política ambiental da autoridade nos campos relevantes e as prioridades que pode orientar a tomada de decisão;

3. Identificação dos métodos pelos quais os objetivos podem ser alcançados, seus custos e outras implicações.

O termo 'auditoria ambiental' é usado com mais frequência, mas também é amplamente mal interpretado como sendo semelhante às normas legais das auditorias financeiras. Atualmente, existem algumas paralelas importantes e diferenças entre auditoria ambiental e atividades de auditoria financeira. Os paralelos incluem, em cada caso, a dependência da metodologia padrão, uma ênfase na verificação da conformidade com as normas e no uso de técnicas de auditoria de som. As diferenças entre auditoria ambiental e financeira têm a ver com a frequência da auditoria, o assunto e a relação de auditor para a operação auditada.

A Auditoria Financeira configura-se como um ramo da contabilidade que revisa as demonstrações financeiras da empresa, assegurando a fidelidade dos registros. O processo de auditoria busca a eficiência das operações, além de comprovar os registros contábeis e dos processos, enquanto a Auditoria Ambiental é uma ferramenta de gestão ambiental definida pela norma NBR ISSO 14.010 como um "processo sistemático e documentado de verificação, executado para obter e avaliar, de forma objetiva, evidências de auditoria para determinar se as atividades, eventos, sistemas de gestão e condições ambientais específicos ou as informações relacionadas a estes estão em conformidade com os critérios de auditoria e para comunicar os resultados deste processo ao cliente", conforme mostra a Tabela 3: 
Tabela 3 - Diferença Primária entre Auditorias Financeiras e Ambientais.

\begin{tabular}{|l|l|}
\hline \multicolumn{1}{|c|}{ Auditoria Financeira } & \multicolumn{1}{c|}{ Auditoria Ambiental } \\
\hline Exigência legal & Ação voluntária \\
\hline Evento anual & Sem frequência fixa \\
\hline Atestado de uma declaração & $\begin{array}{l}\text { Status de conformidade com gestão } \\
\text { expectativas }\end{array}$ \\
\hline Função externa por pessoal externo & $\begin{array}{l}\text { Função interna por interna e / ou externo } \\
\text { pessoal }\end{array}$ \\
\hline $\begin{array}{l}\text { Realizado de acordo com padrões de prática } \\
\text { geralmente aceitos }\end{array}$ & Variação considerável na abordagem \\
\hline Foco em contas financeiras & Foco em questões ambientais \\
\hline
\end{tabular}

Fonte: Adaptado: Anon, (1991).

A auditoria ambiental passou a ser considerada em seu sentido mais amplo. Embora seja aplicado com mais frequência à poluição programas de controle, também pode abranger saúde, segurança, segurança de produtos e até assuntos como segurança de transporte e segurança. As técnicas e sistemas básicos de auditoria ambiental são bem adequados para auditorias de todo o aspecto de potenciais assuntos, se assim o desejar. Embora seja realizado com mais frequência nas operações de fabricação e processo, também pode ser realizada por indústrias de serviços, setor público (nacional, regional e local), agrícola e uma ampla gama de outros empreendimentos. A auditoria ambiental é mais frequentemente empregada por grandes organizações, mas também pode ser usada com eficácia por médias e pequenas empresas.

Visto que uma das maiores vegetações da terra está localizada no Brasil, um país tropical, com uma biodiversidade grande, a preservação de grande parte desta região é essencial para um equilíbrio ecológico. A auditoria ambiental por sua vez, tende fiscalizar não somente as empresas ativas, mas ate mesmo antes de sua instalação, assim verificando as atividades que podem ser prejudiciais ao meio ambiente como sítios contaminados, subprodutos e desperdícios, esgotos, acidentes, poluições da água, solo subsolo ou ar. Bem como também vistoria dos processos de produção e distribuição, uso de energia, água e medidas de economia, reformas e manutenções de prédios e instalações. Todos os casos deve haver uma avaliação objetiva que determina todas as atividades relacionadas às empresas, se estão de acordo com as normas ambientais vigentes. 
Research, Society and Development, v. 9, n. 8, e918986569, 2020

(CC BY 4.0) | ISSN 2525-3409 | DOI: http://dx.doi.org/10.33448/rsd-v9i8.6569

O licenciamento fornecido pela auditoria é importante porque avalia as conformidades da empresa e se coincidem com as leis, podendo assim aprová-las ou reprová-las. Exercendo também o importante papel a proteção e a conservação da biodiversidade.

\subsection{Tipos de auditoria ambiental}

La Rovere (2011, apud Campos e Lerípio 2009, p. 7), conceitua a Auditoria Ambiental, como sendo '[...] uma ferramenta, que possibilita um 'retrato' instantâneo do processo produtivo, passando a ser possível identificar os pontos 'fortes' e 'fracos' da organização com o meio ambiente.”, e Kuhre (1996) apud Campos e Lerípio (2009, p.7) a defende como “[...] um processo sistemático para obter, avaliar e reportar fatos de conformidade ou não conformidade ambiental, de acordo com algum critério definido previamente".

Dentre os estudiosos dos diversos tipos de auditoria, a tipologia mais utilizada segue abaixo, a qual tem variação de acordo com o que avalia, conforme a Tabela 4:

Tabela 4 - Categorias de Auditoria Ambiental.

\begin{tabular}{|l|l|}
\hline Tipos de Auditoria & Definição \\
\hline Conformidade Legal & $\begin{array}{l}\text { Também conhecida como compliance, avalia a adequação da unidade audi- } \\
\text { tada em relaçâo aos requisitos legaîs aplicáveis. }\end{array}$ \\
\hline Desempenho Ambiental & $\begin{array}{l}\text { Seu enfoque é na avaliação da unidade auditada em relação ao aten- } \\
\text { dimento aos requisitos legais aplicáveis e outros requisitos, além dos } \\
\text { Indicadores de Desempenho Ambiental (IDA). }\end{array}$ \\
\hline SGA & $\begin{array}{l}\text { Avalia o grau de atendimento aos requisitos estabelecidos no Sistema } \\
\text { Gestão Ambiental, sua adequação e eficácia. }\end{array}$ \\
\hline Certificação & $\begin{array}{l}\text { Realizada por Organismo de Certificaçâo Ambiental independente, é muito } \\
\text { similar à de SGA. A equipe de auditoria recomenda ou nâo a certificação } \\
\text { em função da avaliação realizada e dos resultados obtidos. }\end{array}$ \\
\hline Descomissionamento & $\begin{array}{l}\text { No caso de uma desativação (paralisaçâo definitiva das atividades) de } \\
\text { uma organização, são avaliados os danos ao ecossistema e à população do } \\
\text { entorno da unidade, Também conhecida como decommissioning. }\end{array}$ \\
\hline Responsabilidade & $\begin{array}{l}\text { Usualmente chamada de duediligence, seu enfoque é na avaliação do } \\
\text { passivo ambiental. Atualmente, muito aplicada, especialmente, no caso de } \\
\text { fusôes, incorporaçães, compras de organizações. }\end{array}$ \\
\hline Sítios & $\begin{array}{l}\text { Aplicada quando o objetivo é avaliar o grau de contaminação de um deter- } \\
\text { minado local. }\end{array}$ \\
\hline Pontual & $\begin{array}{l}\text { O objetivo, nesse caso, é avaliar as oportunidades de melhorias do } \\
\text { processo produtivo, a otimização da gestão dos recursos. }\end{array}$ \\
\hline
\end{tabular}

Fonte: La Rovere et al., (2001). 
La Rovere (2011), segundo o autor, o objetivo das auditorias ambientais é que define sua classificação, podendo ser as seguintes:

- $\quad$ Auditoria de conformidades legal: é uma maneira onde o auditor busca ferramenta para avaliá-la se as conformidades da empresa são vigentes com a legislação ambiental brasileira;

- Auditoria de desempenho ambiental: consistem na avaliação de conformidades, regulamentos e indicadores de desempenho de responsabilidade ambiental;

- $\quad$ Auditoria de sistema de gestão ambiental: identifica se a organização cumpre com os critérios de sistema de gestão com suas adequações e eficácias;

- $\quad$ Auditoria de certificação: tem como objetivo constatar se a empresa segue as normas mediante a solicitação de certificação desejada;

- $\quad$ Auditoria de descomissionamento: esta tem como função identificar as consequências que a organização danificou ao ecossistema e a sociedade em si, quando a mesma realizou a desativação de suas atividades empresariais;

- Auditoria de responsabilidade: é utilizada para ocasionar aquisições de refinanciamento ou fusões empresariais, avaliando as responsabilidades organizacionais;

- Auditoria pontual: a mesma tem como objetivo realizar a otimização de seus recursos e assim obter melhorias em seu processo produtivo com a minimização da utilização de recursos nos quais necessitam de usufruir de recursos naturais e renováveis;

- Auditoria interna: é realizada pelos reesposáveis, sejam eles internos ou terceirizados, com isso, os prestadores de serviço identificam a veracidade de instrumento de gestão ambiental;

- $\quad$ Auditoria de segunda parte: são realizadas somente por terceiros, os quais tenham valores que necessitam do resultado que é previsto de acordo com a auditoria. Podendo ser citado os fornecedores ou clientes que buscam que o seu produto ou seu representante tenha certificação, e seja comprometido ambientalmente com a sociedade, para que a empresa tenha critérios definidos para uma melhoria no mercado e consumidores finais;

- $\quad$ Auditoria de terceira parte: Fazem certificações, re-certificaçōes e manutenções dos certificados que a empresa possui, geralmente apenas é realizado por órgãos certificadores.

Com a intenção de controlar o processo de observação, medidas e critérios determinados para atingir os objetivos de prevenir a degradação ambiental, que normalmente decorre na falta ou pouco controle do impacto ambiental realizadas nas operações a qual se 
destinam a auditoria ambiental e extremante importante como ferramenta a ser utilizada, demonstradas na Figura 4:

Figura 4 - Processos de Auditoria.

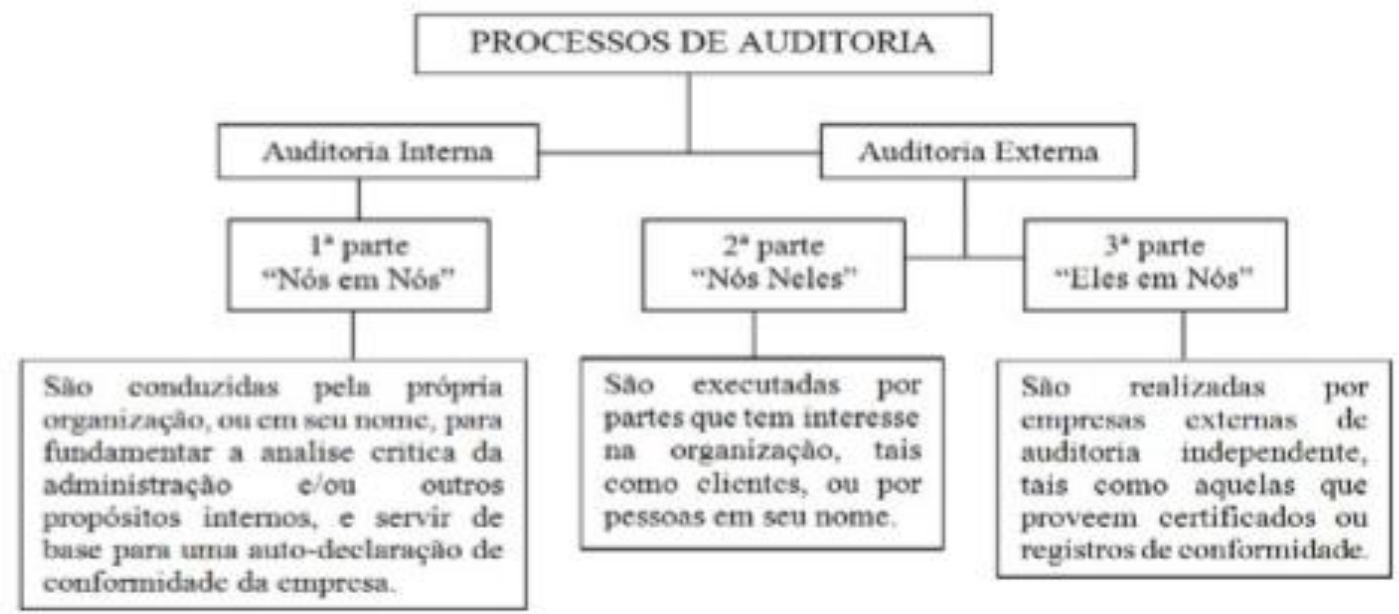

Fonte: Adaptado de ISO 9001 (2000), Sanchez (2011) e Cerqueira (2005).

\subsection{Auditoria ambiental e avaliação de impacto ambiental}

Os vários tipos de auditoria de planejamento ambiental são meios melhorar o enquadramento geral das políticas públicas, regulamentares e administrativas para a gestão ambiental, incluindo AIE. Portanto, pode-se dizer que esse tipo de auditoria ambiental é uma extensão da AIA.

As auditorias ambientais corporativas visam garantir que as empresas envolvidas cumpram essa estrutura, incluindo planos de requisitos. As auditorias ambientais corporativas são uma extensão da conformidade ambiental compromissos ou requisitos, mas não a AIA como tal. Mesmo assim, existem muitos vínculos entre a AIA e as empresas de auditoria ambiental. As auditorias ambientais corporativas geralmente se preocupam em lidar com possíveis impactos futuros; e auditorias são geralmente realizadas em instalações operacionais, enquanto o AIE geralmente é realizado antes de um projeto começa.

A AIA e a auditoria ambiental corporativa, no entanto, geralmente descrevem o status atual de parâmetros em um determinado site; AIA como linha de base, auditoria como referência. Algumas auditorias são realizadas como parte de uma aprovação processo, seja pelas agências reguladoras ambientais, quanto pelas licenças ou garantias operacionais; ou 
pela regulamentação corporativa agências de prospetos, fusões e aquisições corporativas. Da mesma forma, as auditorias ambientais corporativas geralmente envolvem alguma forma de verificação objetiva, geralmente a terceiros; e os documentos da AIA também estão sujeitos a cortes externos por agências governamentais e pelo público. Note-se que muitas pessoas e empresas que geralmente não conduzem empresas de contabilidade e direito ambiental da AIA em particular. Também realiza auditorias ambientais. Em muitos aspectos, o desenvolvimento da auditoria ambiental paralisou o da AIA, mas atrasou-a em uma década ou mais. Os profissionais experientes da AIA são numerosos e existem organizações profissionais internacionais, como a Associação Internacional para Avaliação de Impacto. Auditores ambientais experientes, em contraste, ainda são comparativamente poucos; os cursos de treinamento ainda são bem frequentados e os manuais são muito procurados.

\subsection{Qual importância da auditoria ambiental no gerenciamento de resíduos}

A auditoria ambiental no gerenciamento de resíduos é uma importante ferramenta para à verificação e avaliação da situação do gerenciamento dos resíduos gerados na empresa. Além disso, confronta se a organização segue as normas e legislações pertinentes à gestão de resíduos.

A auditoria ambiental consiste em um conjunto de atividades organizadas, que tem o intuito de verificar e avaliar a relação entre os processos de produção e os aspectos ambientais. Incluindo avaliar se a instituição desenvolve práticas ambientalmente adequadas referentes ao gerenciamento dos resíduos, tais como: a compostagem, a reutilização, a reciclagem e a logística reversa.

\subsection{Auditoria ambiental no gerenciamento de resíduos}

A auditoria ambiental no gerenciamento de resíduos é responsável por avaliar o grau de conformidade de uma empresa com a legislação ambiental e com a sua política na gestão de resíduos.

Necessariamente, a auditoria é um instrumento que possibilita fazer uma avaliação sistemática, periódica, documentada e objetiva da gestão de resíduos. É uma ferramenta muito utilizada para identificar falhas e problemas ambientais no gerenciamento de resíduos para, então, buscar a adequação. 
Research, Society and Development, v. 9, n. 8, e918986569, 2020

(CC BY 4.0) | ISSN 2525-3409 | DOI: http://dx.doi.org/10.33448/rsd-v9i8.6569

Com a auditoria a empresa consegue identificar as fontes de geração de resíduos, sua quantidade e composição. Também, estima à redução na geração, o seu reuso, reciclagem ou compostagem. Bem como, estimar o local de disposição e meios de minimizar os custos que a organização tem com os resíduos.

As normas da série ISO 14000 - Sistema de Gestão Ambiental - SGA, é que rege a auditoria ambiental. A premissa do SGA é a minimização dos efeitos nocivos ao ambiente proveniente das atividades da empresa. Além disso, a norma avalia as consequências ambientais das atividades, produtos e serviços da organização.

Em relação ao gerenciamento de resíduos, a aplicação das normas da séria ISO 14000, especialmente a ISO 14001:2015, é de fundamental importância para identificar e avaliar os procedimentos adotados tanto em relação ao acondicionamento, quanto a destinação final ambientalmente correta dos resíduos gerados.

Já em relação às normas e legislações pertinentes a gestão de resíduos, a auditoria diagnostica e avalia se a organização as cumpre. São verificados os cumprimentos da: Política Nacional de Resíduos Sólidos (Lei $\mathrm{n}^{\circ}$ 12.305, de 02 de Agosto de 2010); NBR 10.004: Resíduos Sólidos - Classificação; a implantação da logística reversa; dentre outras.

A aplicação do SGA permite uma aproximação do utilizado, porem, destacando as diferanças entre o sitema de Gestao Ambeintal e o SGA, procurando uma melhor eficiência com os resultados naturais e suas preocupações com a melhoria nos resultados que a organização alcançará, assim gerando inúmeras vantagens econômicas, ambientais e sociais, conforme mostra a Figura 5: 
Research, Society and Development, v. 9, n. 8, e918986569, 2020

(CC BY 4.0) | ISSN 2525-3409 | DOI: http://dx.doi.org/10.33448/rsd-v9i8.6569

Figura 5 - Diferença da abordagem em Sistema de Gestão Ambiental.

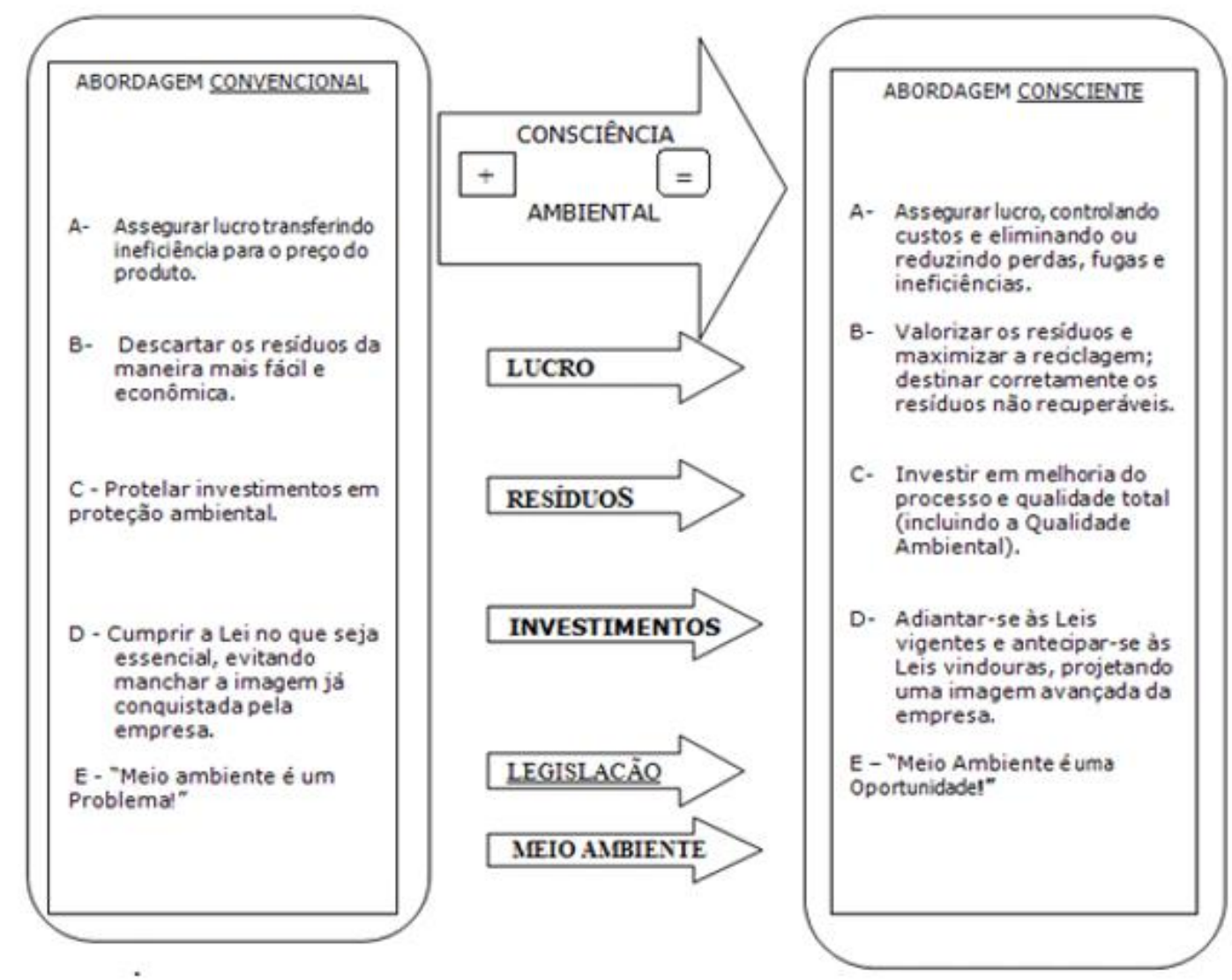

Fonte: Valle (1995) Diferença da abordagem em Sistema de Gestão Ambiental.

\subsection{Vantagens da auditoria ambiental no gerenciamento de resíduos}

Destacam-se como vantagens da auditoria ambiental no gerenciamento de resíduos para as empresas as seguintes:

- identificação e registro das conformidades e não conformidades com as normas e legislação pertinentes;

- prevenção de acidentes ambientais e dos consequentes custos e prejuízos para a imagem da organização caso não seja realizado a destinação correta dos resíduos;

- fornecimento de informações importantes à administração para a implementação da qualidade ambiental e para a alocação de recursos (financeiros, tecnológicos e humanos) para a minimização da geração de resíduos, destinação e disposição final;

- avaliação, controle e redução do impacto ambiental da atividade; 
- minimização dos resíduos gerados e dos recursos utilizados pela empresa na sua destinação e disposição;

- informações ambientais consistentes e atualizadas sobre o desempenho ambiental da empresa. Essas informações podem ser utilizadas para a organização captar investidores. Além disso, podem ser utilizadas para informar órgãos de fiscalização sobre a gestão de resíduos.

\subsection{Procedimentos de auditoria}

Os detalhes de uma auditoria sempre serão diferentes, dependendo do tipo de organização, da natureza e do nível das atividades, e o número de locais. As principais etapas do procedimento de auditoria de temas serão idênticas. Estes foram descrito na ISO 14011.

As atividades de auditoria podem ser divididas nas seguintes fases:
- A. Preparando a auditoria;
- B. Executando a auditoria;
- C. Relatórios.

De acordo com Barbieri (2007), a série ISO 14000 possui diversas áreas de atuação, sendo que cada número da série se refere a uma atividade específica, como, por exemplo, a ISO 14001:2004 é utilizada para a implementação da Gestão Ambiental nas Organizações, A norma ISO 14000 deve se adequar a auditoria ambiental no momento de monitoramento das etapas, com o intuito de acompanhar todo esse processo de forma eficiente, conforme mostra a Figura 6: 
Figura 6 - Ciclo de melhoria continua no sistema de gestão ambiental ISO 14001.

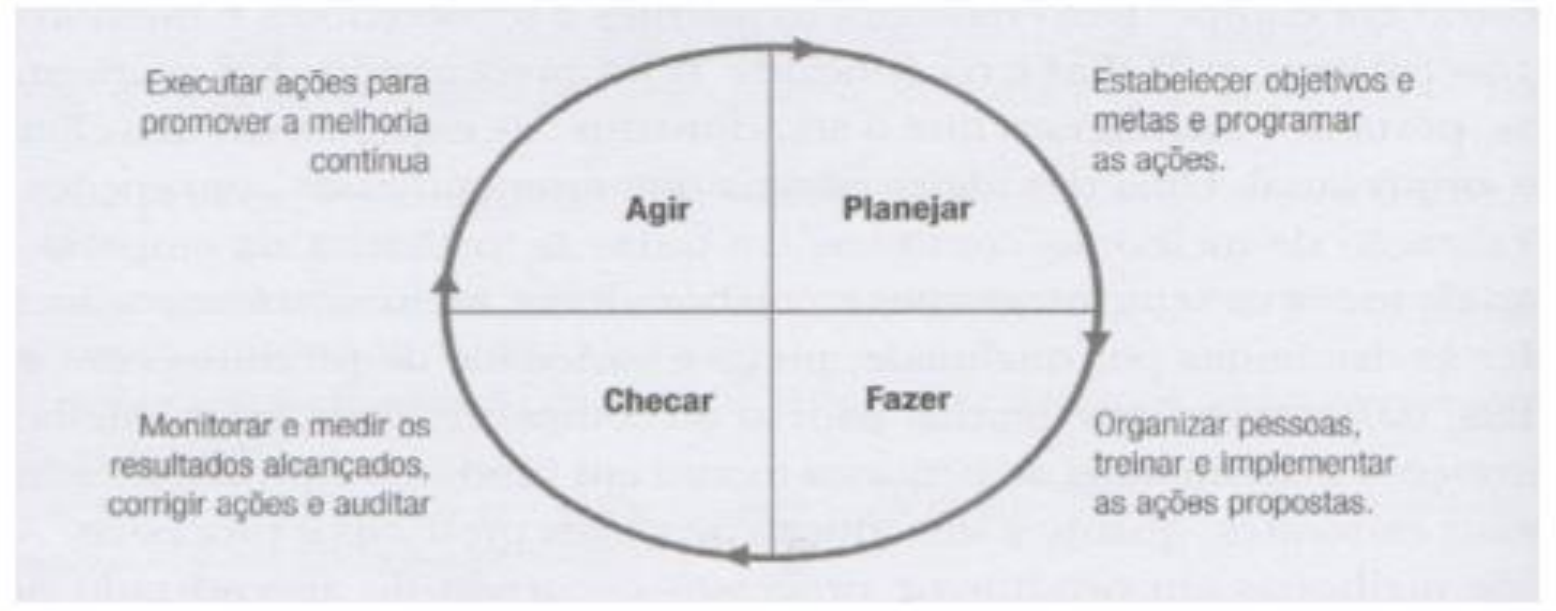

Fonte: Barbieri (2007) Ciclo de melhoria continua no sistema de gestão ambiental ISO 14001

Critérios de qualificação para Auditores Ambientais: A ISO 14012 descreve critérios de qualificação para auditores ambientais. $\mathrm{O}$ documento não exclui nenhum tipo de auditor. Isso significa que o documento é aplicável tanto para auditores externos quanto para auditores internos. Na introdução, no entanto, do documento, indica-se que os auditores internos precisam do mesmo conjunto de competências que os auditores externos, embora eles possam não atender em todos os aspectos aos critérios detalhados descritos no documento. O principal ponto de discussão para chegar ao documento, qual combinação de experiência, educação e treinamento deve ser necessária, mínimo. Por fim, foi decidido:

- selecionar duas combinações de educação e uma experiência;

- ensino médio e 5 anos de experiência de trabalho apropriada. Dependendo do tipo de possível adicional educação ou treinamento completo, a experiência pode ser reduzida em um ano no máximo;

- um diploma e quatro anos de experiência profissional adequada. Novamente, a possível educação ou treinamento adicional concluído pode ser levado em consideração para reduzir a experiência de trabalho necessária. Nesse caso, a redução máxima não deve exceder dois anos. 


\subsection{Frequência de auditoria}

As frequências da auditoria dependerão do tamanho e complexidade das operações, do potencial ambiente, aspectos e impactos da empresa e estágio de desenvolvimento do sistema de gestão. Por exemplo, para uma operação de alto risco ou em que o sistema de gerenciamento seja novo, seria apropriado auditar cuidadosamente o sistema anualmente. Para uma operação de baixo risco, uma auditoria completa pode ser realizada a cada três anos.

\section{Método de Pesquisa}

\subsection{Problema da Pesquisa}

A analise da pesquisa sobre o problema apresenta as etapas, classificações e tipos de auditorias ambientais e as vantagens e desvantagens de sua implementação, com a intenção que possamos entender as principais funções que se tem quando feito a auditoria ambiental e a importância de uma auditoria rigorosa sobre quesitos ambientais no atual cenário empresarial e com isso possamos compreender qual a função dos profissionais que exercem essa função de auditoria.

\subsection{Tipo de Pesquisa}

A metodologia utilizada neste artigo foi a de pesquisa acadêmica qualitativa exploratória, foram utilizadas informações obtidas por meio de pesquisa bibliográfica com levantamento de dados a partir de livros, revistas, artigos de periódicos e consulta de materiais disponibilizados na internet. Segundo Gil (2000, p.44) "pode-se definir pesquisa como o processo que tem por finalidade descobrir respostas para os problemas mediante a utilização de procedimentos científicos". Para Gil (2002, p.44), “[...] a pesquisa bibliográfica é desenvolvida com base em material já elaborado, constituído principalmente de livros e artigos científicos". A principal vantagem da pesquisa bibliográfica está no fato de permitir ao investigador a cobertura de uma gama de fenômenos muito mais ampla do que aquela que poderia pesquisar diretamente. Tais vantagens revelam o compromisso da qualidade da pesquisa. Assim, além de permitir o levantamento das pesquisas referentes ao tema estudado, a pesquisa bibliográfica permite ainda o aprofundamento teórico que norteia a pesquisa. 


\subsection{Justificativa}

O presente trabalho foi realizado pontuando sempre que a auditoria pode ser realizada tanto internamente quão no ambiente externo, sendo realizada por uma pessoa ou por uma equipe no qual pode ou não estar incluída no quadro de funcionários. A empresa que obtém resultados positivos a organização passa por certificações, o que influência no desempenho de seus funcionários, a expectativas do seu consumidor final, tendo em vista que a organização certificada ambientalmente tem um espaço maior dentro da sociedade e uma visão totalmente diferente das demais.

A Auditoria ambiental pode demonstrar-se um divisor de aguas em relação à competitividade que envolve todos os setores dos processos produtivos, juntamente com ações de politicas que visam a proteção ambiental, seja voluntaria ou involuntariamente. A implementação da Auditoria Ambiental colabora claramente com as organizações influenciando as ações econômicas e ambientais em ações de prevenção contra prováveis malefícios ambientais

\section{Análises}

\subsection{Instrumentos de coleta de dados}

Os dados foram visando sempre à busca pela avaliação do desempenho, concordância legal, comprometimento da organização das políticas ambientais de uma empresa. No presente artigo, temos como proposito gerar a compreensão da importância e das formas que são abordadas a auditoria ambiental.

Os indicadores de desempenho ambiental visam demonstrar as práticas organizacionais no sentido de minimizar os impactos ao meio ambiente decorrentes de suas atividades. Esses indicadores referem-se ao uso de recursos naturais demonstrados em valores monetários e em valores absolutos de quantidade ou consumo, considerando também as iniciativas de gerenciamento ambiental, os impactos significativos relacionados ao setor da atividade e as respectivas ações de minimização (Gasparini, 2003). 


\subsection{Análise dos dados}

Abordando sempre de forma conceitual, os referenciais que nos é definido por estudiosos do ramo e com isso podemos demonstrar como a auditoria é de suma importância para a gestão ambiental de uma organização.

É com base nos resultados das auditorias que os responsáveis pela gestão realizam a análise crítica do sistema, buscando avaliar se ele é ou não capaz de gerar medição, se satisfaz a todos os requisitos metrológicos e se está adequado para a geração de evidências que apoiem decisões de aprimoramento. (Cerqueira, 2005)

\section{Conclusão}

Como citado por Barbiere (2007), auditoria não é obrigatória, porém a mesma se torna um diferencial para a organização. Entretanto, se é obrigatório apenas quando a auditoria é necessária afim de legalização no setor judicial da empresa, em setor publico ou órgão ambiental.

Contudo, podemos identificar que ao decorrer de toda analise bibliográfica, foi se encontrado diversos conceitos nos quais podemos entender que independente da visão autoral, todos e quaisquer metodologias abordadas denominam a mesma estrutura de auditoria. Um campo essencial para o desenvolvimento correto da ecologia brasileira, cujos principais objetivos são a fiscalização, avaliação para determinar operações empresariais que atendem aos critérios solicitados pela gestão ambiental legislativa vigente, tratando-se de procedimentos realizados internamente ou externamente para expressar analises claras e objetivas.

Definimos a auditoria ambiental como uma ferramenta na qual auxilia a organização para que execute de forma eficiente e eficaz a qualificação e a licenciatura de qualificações técnicas.

Com resultados satisfatórios e a periodicidade das auditorias, a tendência é que se crie uma cultura organizacional voltada a preocupação ambiental e um maior conhecimento das normas e leis relacionadas ao assunto por parte dos funcionários.

Ficou evidenciada a importância da Auditoria Ambiental no contexto de gestão para utiliza-la como instrumento de verificação de suma relevância para inúmeras situações que norteiam as organizações. Sendo efetuada segundo as normas e padrões estabelecidos e 
houver um investimento dos auditados neste processo, as desvantagens serão sobrepostas através das inúmeras vantagens obtidas.

Por fim, definimos que a elaboração deste artigo nos permite entender que as obrigações empresariais com o meio ambiente é de suma importância para analise de funções, sendo assim podemos ressaltar que a auditoria ambiental só se fez presente quando a sociedade entendeu a necessidade de um avanço tecnológico para uma capacitação empresarial, pois a mesma quando certificada e de acordo com as vigências necessárias garantindo a conscientização do seu meio, funcionários, sociedade e afins, para que com isso tenhamos a prevenção e a preservação do meio ambiente e dos recursos naturais nele existente.

Mais estudos deverão ser realizados no âmbito da gestão ambiental e da certificação, sistemas e normas. As vantagens não são percebidas somente pelas empresas, mas por toda a sociedade, uma vez que os riscos oferecidos à saúde e ao meio ambiente tornam-se menores. Levando-se em consideração o potencial de aplicabilidade que a norma traz em seu próprio escopo, propondo-se a abranger todos os tipos e portes de organização, estudos como estes são muito importantes, especialmente em países em desenvolvimento como o Brasil.

\section{Referências}

Anon. (1991) Introdução à auditoria ambiental, Guia da ICC para uma auditoria ambiental eficaz, 3-9

Associação Brasileira de Normas Técnicas. (1996). Família de normas ISO 14000. NBR ISO 14000. Rio de Janeiro.

Associação Brasileira de Normas Técnicas. (2004). NBR ISO 14001: Sistemas da gestão ambiental - Requisitos com orientações para uso. Rio de Janeiro: ABNT.

Associação Brasileira de Normas Técnicas. NBR ISO 14001: Sistemas

Associação Brasileira de Normas Técnicas. (2012). NBR ISO 19011: diretrizes para auditorias de sistema de gestão da qualidade e/ou ambiental. Rio de Janeiro: ABNT. 
Barbieri, J. C. (2007). Gestão Ambiental Empresarial: conceitos, modelos e instrumentos. 2. ed. São Paulo: Saraiva. 1.

Brasil. TCU. (2001). Manual de Auditoria Ambiental do Tribunal de Contas da União. Brasília: TCU.

Campos, L. M. S., \& Lerípio, A. A. (2009). Auditoria ambiental: uma ferramenta de gestão. São Paulo: Atlas.

Cerqueira, J. P., \& Martins, M. C. (2005). Auditorias de sistemas de gestão - ISO 9001, ISO 14001, OHSAS 18001/IEC 17015. Rio de Janeiro: Qualitymark.

Conselho Nacional do Meio Ambiente. (2020). (Brasil) Resolução Conama no 306, de 5 de julho de 2002. Diário Oficial da União, Brasília, DF, 10 jul. de 2002. Recuperado de < http://www.mma.gov.br/port/conama/> Acesso em: 15 de maio de 2020

De Moor, P., \& De Beelde, I. (2005). Environmental auditing and the role of the accountancy profession: a literature review. Environmental management, 36(2), 205-19, ago. 2005.

Gil, A. C. (2007). Como elaborar projetos de pesquisa. 4. ed. São Paulo: Atlas.

Hillary, R. (1998). Environmental Auditing: Concepts, Methods and Developments. International Journal of Auditing, 2, 71-85.

Jacobs, M. (1991). Auditorias Ambientais Saúde Ambiental. 165-168.

Kuhre, W. L. (2009). ISO 14010s environmental auditing. PTR-PH, 1996. In Campos, L. M. S., \& Lerípio, A. A. Auditoria ambiental: uma ferramenta de gestão. São Paulo: Atlas.

La Rovere, E. L. (Coord.). (2011). Manual de auditoria ambiental. (3a ed.), Rio de Janeiro: Qualitymark.

La Rovere, E. (2001). Manual de auditoria Ambiental. Rio de Janeiro: Qualitymark. 
Martins, Panorama brasileiro da auditoria ambiental / Gaudêncio José Pinotti Martins. Campinas, SP: [s.n.], 2015. NORMA ISO 19011:2012. Recuperado de <https://qualidadeonline.files.wordpress.com/2009/12/iso19011.pdf>.

Martins, S. R., Soler, A. C. P., \& Soares, A. M. (2001). Instrumentos tecnológicos e jurídicos para a construção da sociedade sustentável. In Viana, G., Silva, M., \& Diniz, N. (Org.) O Desafio da Sustentabilidade. Um debate sócio ambiental no Brasil. São Paulo: Funda- ção Perseu Abramo.

Oliveira Filho, M. L. (2002). A auditoria ambiental como ferramenta de apoio para o desempenho empresarial e a preservação do meio ambiente: uma abordagem contábil e gerencial em indústrias químicas. Monografia. Universidade de São Paulo, São Paulo. 2002.

Ross, M. A. 1996 ISO 14000: Padrões de classificação ambiental Ross, Ltd., Gary, TN 37615, EUA.

Sanchez, A., et al. (2011). "Innovation Management Practices, Strategic Adaptation, and Business Results: Evidence from the Electronics Industry." Journal of Technology Management \& Innovation, Santiago, 6(2).

Seiffert, M. E. B. (2010). Gestão ambiental: instrumentos, esferas de ação e educação Ambiental. São Paulo: Atlas.

Valle, C. E. (1995). Qualidade ambiental: como ser competitivo protegendo o meio ambiente. São Paulo: Pioneira.

Vilela, A. J. (2013). Auditoria Ambiental: Uma Visão Crítica da Evolução e Perspectiva da Ferramenta. In: Alcir Vilela Junior; Jacques Demajorovic. (Org.). Modelos e Ferramentas de Gestão Ambiental: Desafios e Perspectivas para as Organizações. $3^{\circ}$ ed. São Paulo: Editora SENAC, 147-168. 
Research, Society and Development, v. 9, n. 8, e918986569, 2020

(CC BY 4.0) | ISSN 2525-3409 | DOI: http://dx.doi.org/10.33448/rsd-v9i8.6569

Porcentagem de contribuição de cada autor no manuscrito

Márcio Magera Conceição - 40\%

Evandro Ferigato - $40 \%$

Joelma Telesi Pacheco Conceição - 10\%

Alessandro Marco Rosini - 10\% 